\title{
Why mines should look at total life to achieve tailings facility closure
}

\author{
SE Aitken Beca Ltd, New Zealand \\ JP Burr Beca Ltd, New Zealand
}

\begin{abstract}
Dewatering tailings is typically given only a nominal assessment and eliminated as too expensive as a tailings management option because of its perceived upfront capital cost. In fact, there is often a compelling business case for constructing a dry tailings storage facility if the value of reduced risk throughout the operating life and achieving closure are considered holistically.

It is common practice for mines to store tailings waste as a fluid slurry behind earthen embankments or in depleted mine pits. Looked at purely from an upfront cost perspective, this is generally the most economical option. However, look at the same facility long-term and it is a different story. Unless mine owners view tailings management from a total cost/benefit perspective from cradle to grave, their risk analysis of what is considered an appropriate tailings management solution for start-up could be very short-sighted.

A dewatering approach that extracts most of the liquid and changes tailings from a fluid to a soil product, offers many mine sites substantial long-term benefits. Dewatering facilities can be introduced at the start of a project or during operations to transition away from slurry management, and each site should be considered on a case-by-case basis.

As public expectations for standards of remediation and mine closure get higher, mining executives would be remiss if dewatering tailings is not considered as an option when deciding tailings management and closure strategies.
\end{abstract}

Keywords: closure, dewatered tailings management, dry stack

\section{$1 \quad$ Closure planning framework}

Typically, overall project closure planning stays at a concept level until a few years out from implementation at which stage the project would go through increasingly developed design to implement the desired closure conditions. Ideally, closure planning throughout the project life would involve ongoing monitoring and review to align with the maturity of the project, accounting for defined elements of progressive rehabilitation. The recently revised framework suggested by the International Council on Mining and Metals (ICMM) is shown in Figure 1 and illustrates this process of planning, implementation, and review.

At each stage of the mine life, ICMM suggests that there should be an understanding of how temporary or sudden closure could affect the closure plan. Often this is driven by independent auditors requiring an understanding of a company's current environmental rehabilitation obligation rather than a routinely updated process within normal operations.

The initially defined life-of-mine (LOM) for a project is essential to provide boundaries in time, footprint, and value to assess the viability and cost for a project start-up and operations. However, a project closure plan defined by an initial LOM may have little long-term meaning due to continued ore exploration and LOM extensions. Relevance is maintained by reviewing and updating the plan throughout operational life changes.

The key aspect for industry to focus on is progressive closure throughout operations. This captures the essence of the closure plan being a living document, it encourages breaking down a project during operations 
into manageable time capsules of closure, it presents an opportunity to benchmark against existing practices and to consider new approaches to embrace going forward.

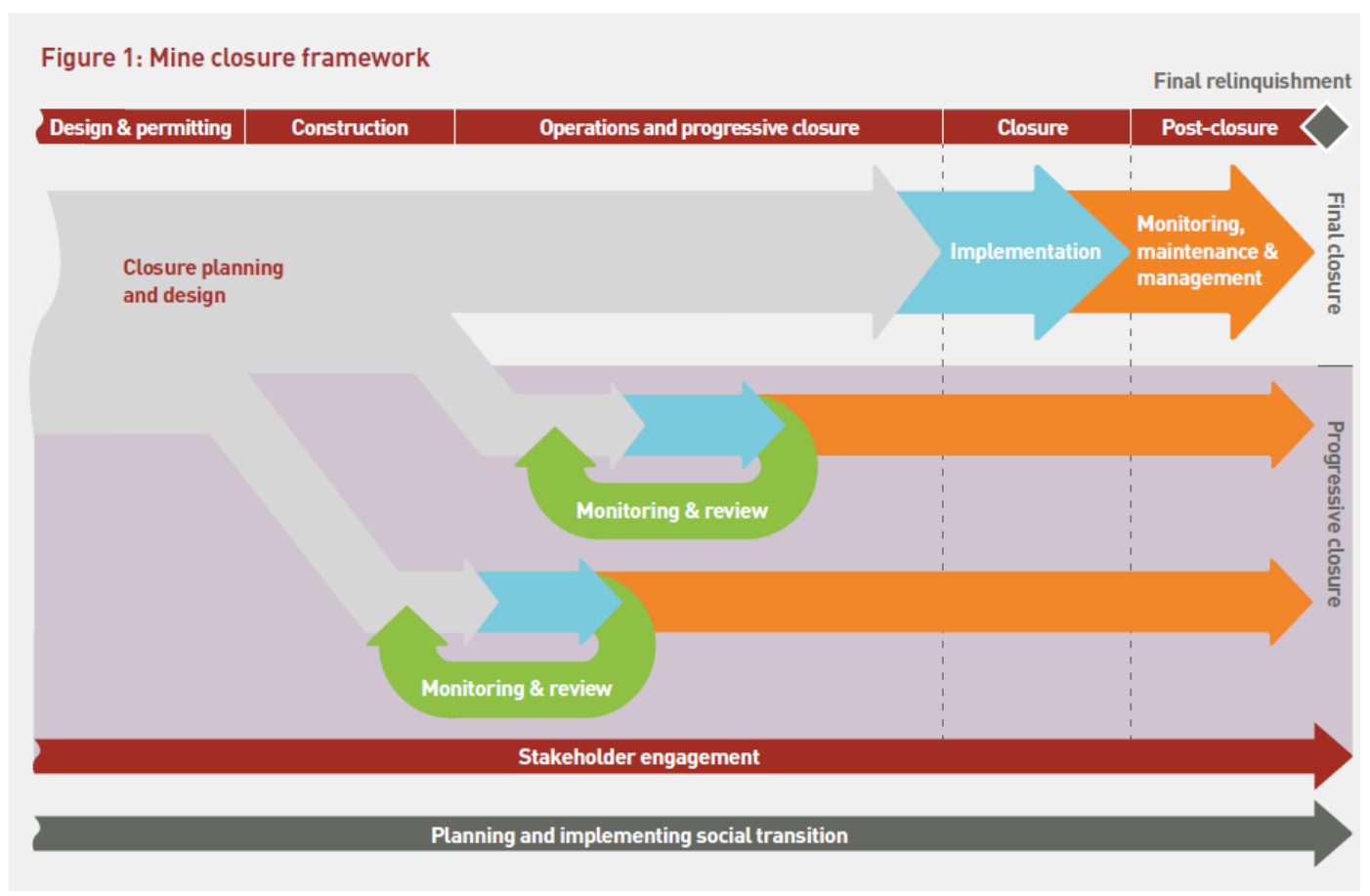

Figure 1 Mine closure framework (International Council on Mining and Metals 2018)

\section{Current practice}

Increasing numbers of organisations are committing to understanding and adopting principles of project closure with a view to subsequent land use. There are also those who linger behind with development of a closure plan and are primarily driven by the need to satisfy legislative requirements. Organisations may also default to a 'care and maintenance' status rather than officially 'close', or in the worst case, abandon the site and leave the local authorities to manage and bear the cost of restoration.

Common practice in preparing a closure plan cost estimate at the project development stage has been to estimate the area of the disturbed footprint remaining at the end of the LOM. Credit is given to areas of rehabilitation and progressive closure that are estimated to have occurred throughout the project operations. A nominal cost per hectare is applied to estimate a provision for closure as an element of the total project cost, and in terms of cash flow, as a concentrated spend at the end of the project operations.

This approach may be adequate for the mine pit area, ore preparation and process plant facilities, ports, linear infrastructure and dry stack tailings storage facilities, etc. Closure of these facilities likely requires minor soil contamination treatment, burial, surface reshaping, revegetation, and walk-away closure with little or no ongoing monitoring.

However, a much larger cost per hectare is required to close conventional slurry tailings storage facilities, being those that comprise a pond with heavy fluid retained behind earthen embankments. This type of tailings facility is very much normal practice in the industry at present.

Slurry tailings are left to settle and passively gain strength under self-weight consolidation. Water is released from the tailings and returned to the process plant for re-use. It is not unusual to encounter assumptions that the tailings provide a stable surface to enable access for closure activities shortly after deposition has ceased. The reality is active mechanical intervention, for example dredging or wellpoint dewatering, is most likely required to physically stabilise the tailings beaches and pond to support the closure process.

The focus of this paper is on tailings storage practices, and of these, conventional slurry storage poses the largest liability in closure, particularly facilities that retain saturated tailings behind an earthen embankment. 
Many are constructed as a first ex-pit facility to initiate the production cycle with the future intent to store mine tailings in depleted pits. Mined-out pits used as slurry tailings disposal areas are often closed as a wetland or lake features. Many ore bodies are hosted in rock that is potentially acid forming on exposure to oxygen and storage of potentially acid forming rock and tailings is traditionally under a water cap to deter the formation of acid drainage.

Failures of slurry tailings facilities have devastating consequences, the most recent in Brazil earlier this year with the loss of many lives. An outcome in response to these failures is that legislation in key mining jurisdictions is evolving to now require, for example, that 'dry stack' tailings management is considered as an option in new projects, that pond liners are required for leachate control, and that upstream construction of tailings embankments is forbidden, along with other measures aimed at reducing social and environmental risk.

While planning for closure is getting increasing visibility, as an industry, we still have a way to go to encourage operating or new mines to adopt new technologies enabling closure friendly tailings management earlier in the project lifecycle. The encouraging outcome of looking for better ways to manage tailings is the progress being made in dewatering equipment manufacturing. Robust and commercially available equipment can handle large volumes of tailings that produce 'dry' filter cake, which is used as a construction material to build stable landforms. This enables closure to be a natural and achievable final step in relinquishing the mine lease to future owners.

The following section discusses tailings behaviour to provide context around closure.

\section{Tailings continuum}

The chart shown in Figure 2 illustrates the continuum (Davies \& Rice 2001) as an increasing amount of water is removed from the tailings. Each category has its benefits and disadvantages as a function of transitioning from a fluid-like slurry with some soil in the water (tailings slurry) to a soil-like product with some water in the soil ('dry' filter cake).

Tailings Continuum (after Davies \& Rice, 2001)

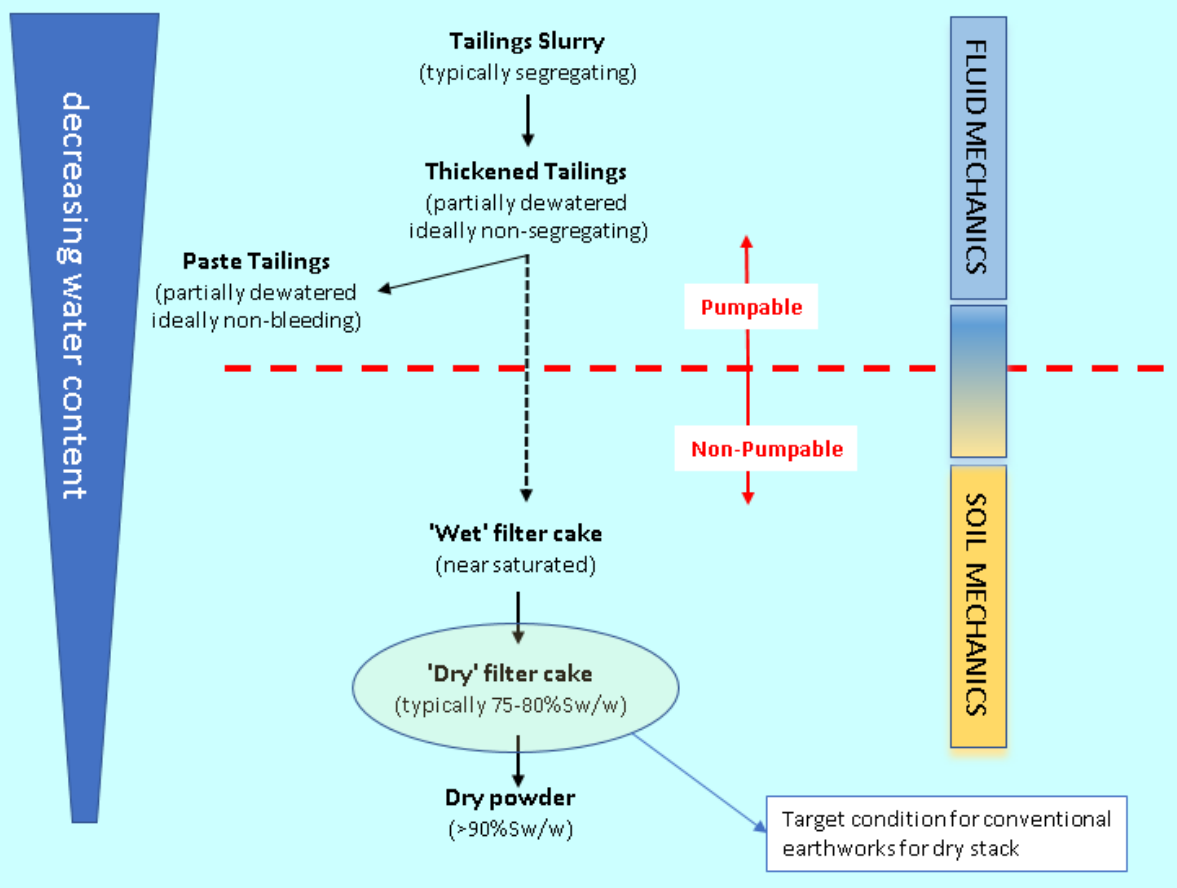

Figure 2 Tailings continuum (after Davies \& Rice 2001) 
Slurry tailings require pumps, pipes, and containment and tend to have the lowest capital expenditure (CapEx) and ongoing operational expenditure (OpEx). Water management can be complex and contact water reclaim from the tailings pond is inefficient. During operations, construction of crest raises along with pond and beach management requires an effective handover from the designers, seepage is likely to occur requiring collection and treatment, plus end-of-life rehabilitation is difficult.

Drier tailings management introduces relatively high initial CapEx and ongoing higher OpEx, with the tailings being dewatered and transported typically by conveyors and/or trucks. The behaviour of the material with increasing dryness (below the red dotted line on the chart) can be likened to building sandcastles on a beach. The 'wet' filter cake is like building them in the water's edge whereas the 'dry powder' is like the upper beach zone, well above the water line. Neither of the conditions is conducive to building strong sandcastles. The strongest sandcastles are built with material that has just the right amount of water in it and is represented by the 'dry' filter cake condition shown in the chart. The tailings storage facility constructed with dry cake enables simple water management and efficient water recovery, has negligible seepage through the stable landform, and progressive rehabilitation is possible at a low cost.

Photos illustrating an example of the different consistency of tailings as a slurry and as a dry filter cake are shown in Figure 3.

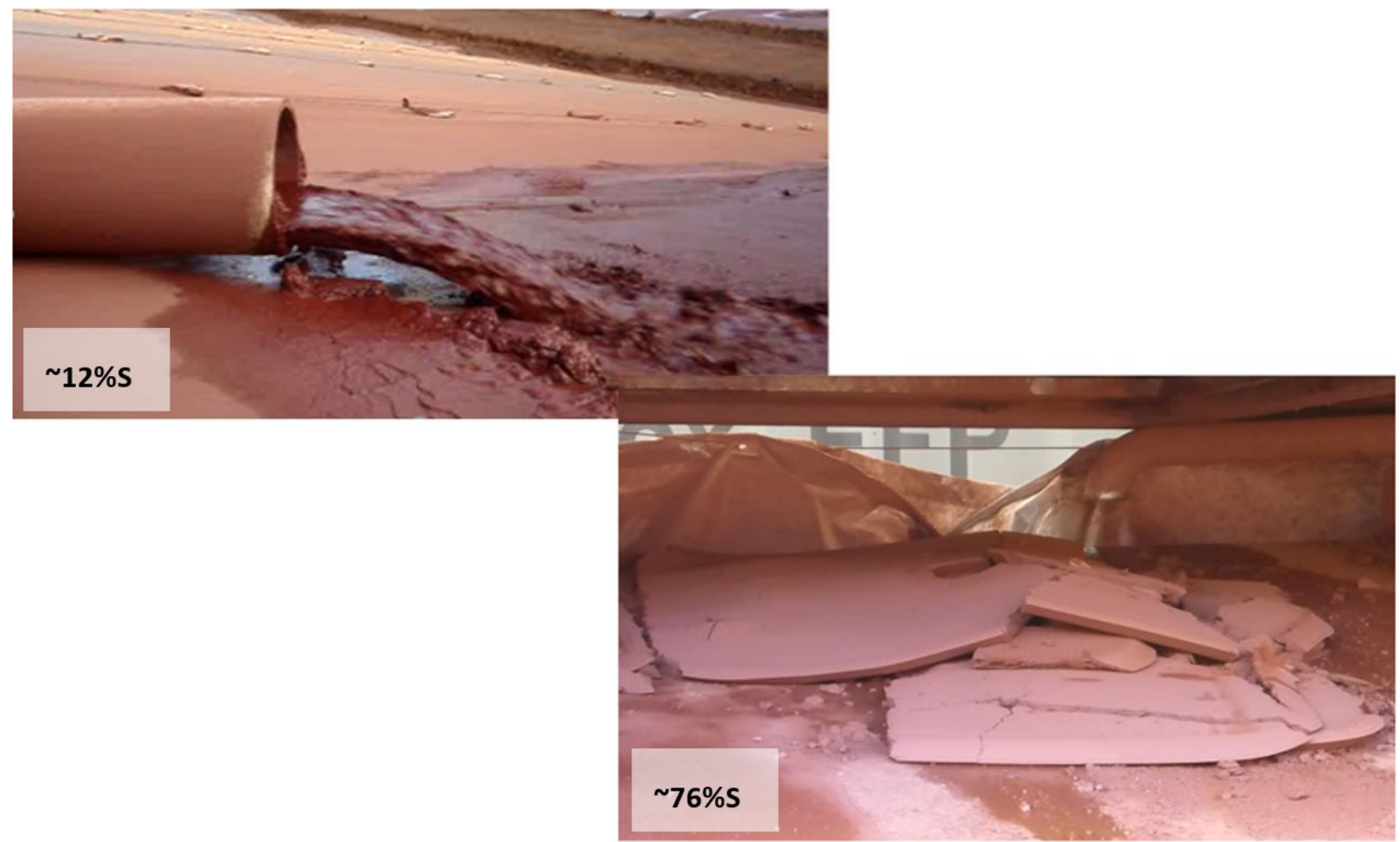

Figure 3 Laterite nickel tailings as slurry and as filtered dry cake (Aitken \& Kemeid 2016)

As an illustration, using nickel laterite silt tailings with $80 \%$ of the particle sizes passing $30 \mu \mathrm{m}$, the categories can be broadly banded by solids content by total weight ( $\mathrm{S} \% \mathrm{w} / \mathrm{w})$. Slurry tailings would be around $30 \% \mathrm{Sw} / \mathrm{w}$, thickened tailings at around 50\% Sw/w; 'wet' filter cake at around $60 \% \mathrm{Sw} / \mathrm{w}$, and 'dry' filter cake is in the order of $75 \% \mathrm{Sw} / \mathrm{w}$. This will be slightly different for other mineral tailings, e.g. coal will be slightly lower accounting for lower specific gravity. In all cases, however, guidance aside, the behaviour of the tailings needs to be established for site-specific conditions.

The strength of a soil material increases measurably once water is removed. This is illustrated, for example, with nickel laterite tailings in Figure 4. The highest strength and densest packing of the particles occurs at an optimum moisture content and corresponding solids content at approximately $76 \% \mathrm{Sw} / \mathrm{w}$. While the strength is still high with continued water removal beyond this optimum, the ability to compact the material reduces. 


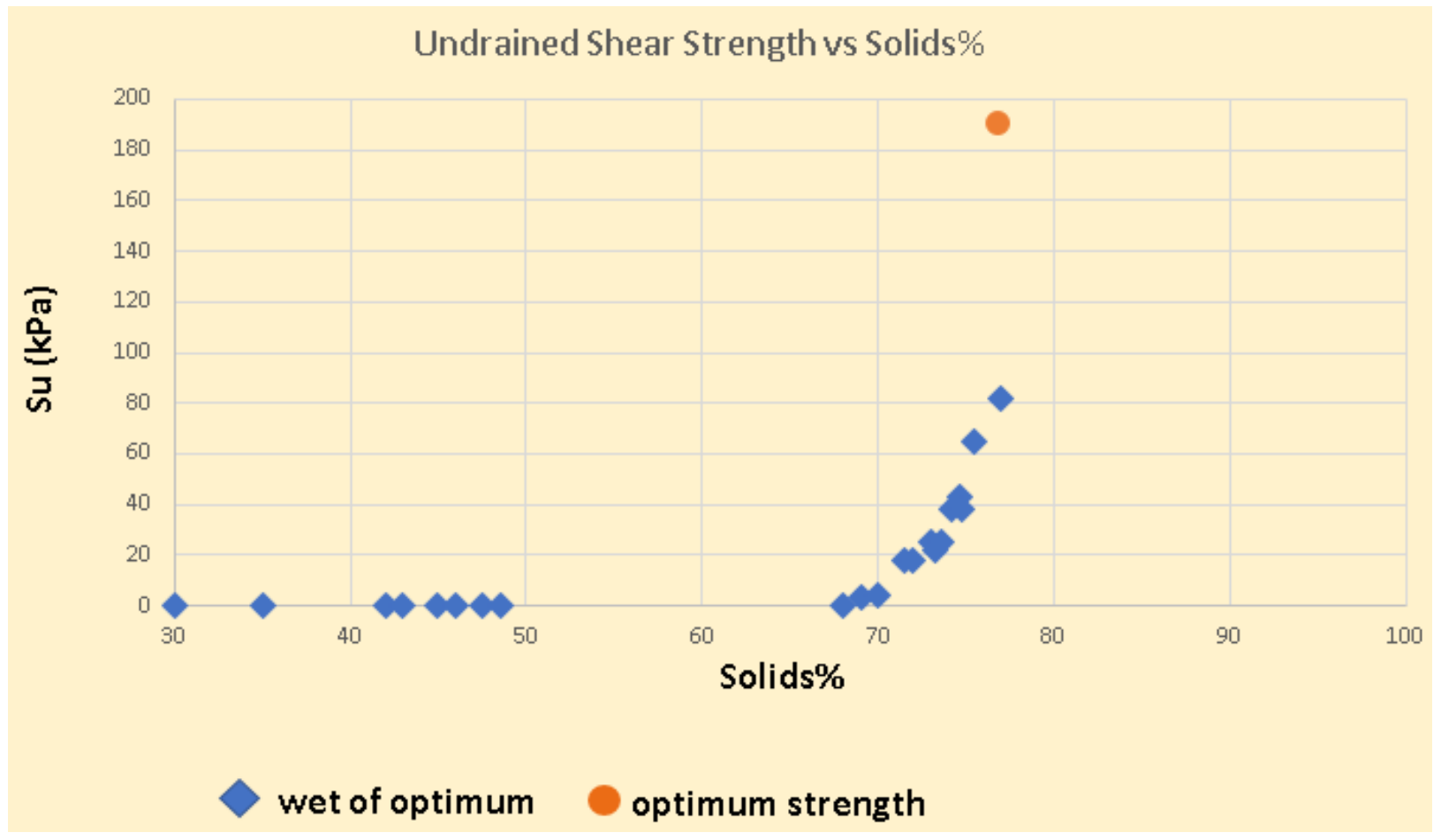

Figure 4 Illustration of strength gain versus increasing solids content (S \%w/w)

Closure is essentially about increasing the solids content of the tailings to improve strength to a condition that will support loadings, either a maximum during the capping process or as defined by future use.

Self-weight consolidation of tailings, even starting as thickened tailings, can typically only reach a still saturated 'wet' filter cake condition in a practical lifetime prior to needing to be capped.

In order to provide a cap over a slurry tailings facility, there may be a need to build out over the soft tailings beaches formed through tailings deposition. A layer placed over the tailings surface to accelerate consolidation and convey porewater released from the in situ drainage system requires delivery and placement of drainage aggregate. This would be hauled in by truck, likely stockpiled and placed using long-reach diggers until a platform of sufficient strength is developed to support heavier vehicles to place a contoured landform and capping layer prior to revegetation. This sequence of stepping out over the consolidating tailings repeats until the facility is fully covered.

The same process applies if a transition from slurry to dry stack management is implemented. The advantage of implementing this transition earlier in operations is that the landform is constructed using the tailings itself.

Tailings typically need to be close to a dry filter cake condition to contemplate vehicle access or target a bare minimum soil strength of at least $20 \mathrm{kPa}$ to carefully enable the lightest of vehicles. For comparison, a CAT D5 swamp dozer requires around 50kPa bearing support.

In conclusion, closure is effectively transitioning the consistency of the tailings to a dry cake condition at least for a substantial depth from the surface of the facility.

\section{$4 \quad$ Dry stack (cake) tailings}

Tailings that are preconditioned to an optimum solids content prior to disposal into waste storage facilities can immediately support vehicle traffic. This requires removing water from the tailings through various mechanical methods, the most effective usually being pressure filtration.

This approach offers many advantageous outcomes, either from project start-up or transitioning from an initial start-up as a slurry facility: 
- Dewatered tailings can be 'dry-stacked' into earth mounds/waste dumps and shaped into landforms in a reduced footprint.

- Dewatering equipment manufacturers are continuously improving their capability to treat high volumes of tailings and are able to produce soil-like material at a target moisture content (defined by the properties requirements for dry stack construction).

- May enable immediate water recovery for re-use in process which can reduce raw water demand and/or contribute to a secure source of raw water.

- Costs to set up the necessary infrastructure to implement tailings dewatering are reducing and whole-of-life tailings management solutions are becoming more cost competitive and attractive with social and environmental benefits.

- This soil-like material is amenable to normal earthworks construction practices that widens the pool of engineers and contractors who are able to provide design and construction services with a hand-off to the client operators.

- A dry-stacked tailings facility eliminates the need for retention embankments.

- Removes risk of embankment failure and downstream inundation with consequent social and environmental damage and risk to corporate reputation.

- Potentially improves water management practices in reducing contact water quantities (rain that lands on the tailings area) and diverting surface water runoff.

- Enables progressive closure so reduces timeline to closure and relinquishment to future land users.

- A transition from slurry storage to dewatered tailings management can be implemented once the project is generating cash flow, process variability is stabilised, and more attention is being given to forward thinking closure designs.

- A dry stack facility is more robust in seismically active regions and less sensitive to settlements on soft foundations.

- The approach is more acceptable to community stakeholders and legislators, providing substance to a 'social licence to operate'.

So why are organisations only slowly considering dry cake tailings management or transitioning from slurry to dry cake tailings management earlier in their project cycles to take advantage of the clear benefits it provides?

The general front-of-mind perception is that dewatering is too expensive with upfront CapEx and high OpEx. The option tends to be eliminated without developing the concepts of dry cake tailings management to a level where informed decisions can be taken.

Dry cake tailings management tends to not be considered for projects in tropical climates because the perception is 'it rains all the time'. Interestingly in wet climates, the limiting parameter in earthworks construction appears to be productivity and managing standby time, rather than the physical construction works. This is evidenced by the construction of large earthworks projects in wet, tropical climates as a matter of course, so it is a small mental hurdle to adopt a long-term earthworks program using dry cake tailings as the building material.

One last thought is dry cake tailings management is eliminated because it is considered 'novel', disrupts the ease of implementing traditional management practices, and there is an understandable reluctance to be the first to prove something new. 


\section{$5 \quad$ Closure of a slurry tailings storage facility}

An essential ingredient for closing an ex-pit tailings facility is to provide a stable foundation for the final landform on which revegetation and surface water management facilities can be established.

Each project has its own dynamics, tailings properties, geometry, climate, access, equipment, and other parameters so must be assessed in its own unique set of circumstances.

Some principles considered in an assessment of individual tailings storage project signatures might include:

- Under self-weight consolidation, facilities typically store more water than solids by volume.

- Rate of filling of the facility affects the ability and timeframe for tailings to settle and consolidate.

- Tailings from process are generally silt sized with some variable fraction of clay sized particle sizes and have low permeability.

- The tailings can blind off surfaces they settle against acting as a barrier to seepage and consolidation.

- Ponds with liners permit only one-dimensional seepage to the tailings surface, slowing down the consolidation process geometrically in time.

- The formation of a crust on the surface of tailings can inhibit consolidation and water recovery. The crust can also present a false sense of security for its ability to support repeated vehicle loading.

- Active intervention to reduce porewater content is likely required to enhance the undrained strength of the tailings to support equipment access to reshape and cap the tailings footprint.

- Wet closure features retained behind an embankment create saturated conditions producing leachate seepage that may require capture and treatment before release to the environment, and embankment stability monitoring and maintenance will continue indefinitely.

- Pressure on legislators to sign-off for relinquishment for future users.

Over and above the physical conditions, there are legislative conditions that vary across jurisdictions. Many require these facilities to survive and perform in perpetuity. Compare this with bridges and significant buildings with design lives of maybe 100 years. A tailings dam must contain a very large storm event and with futuristic estimates to include the influence of climate change. Where is it defined 'when is a dam no longer a dam?' and when is it appropriate to cease regular dam safety inspections which might signal the facility has transformed to a landform available for another use?

There are examples where capping and dry surface closure over a conventional slurry tailings facility have been achieved but has mostly required much more effort and cost than ever anticipated at the outset of the project.

The final overlay for designing and implementing closure activities is the general reticence by corporations to spend money on non-revenue generating facilities. It is important for them that funds allocated to closure are spent effectively, but it can also be that closure activities are underfunded.

An illustrative cost profile is shown in Figure 5. Slurry deposition is assumed to occur up until the active closure phase at which time, substantial investment is required to deliver a closure landscape. The prolonged post-closure monitoring phase requires a continuous stewardship long after production has ceased. The final expenditure is an allowance for the reporting necessary to relinquish the facility. 


\section{Example Illustration of Expenditure for Closure of Slurry Tailings Storage Facility}

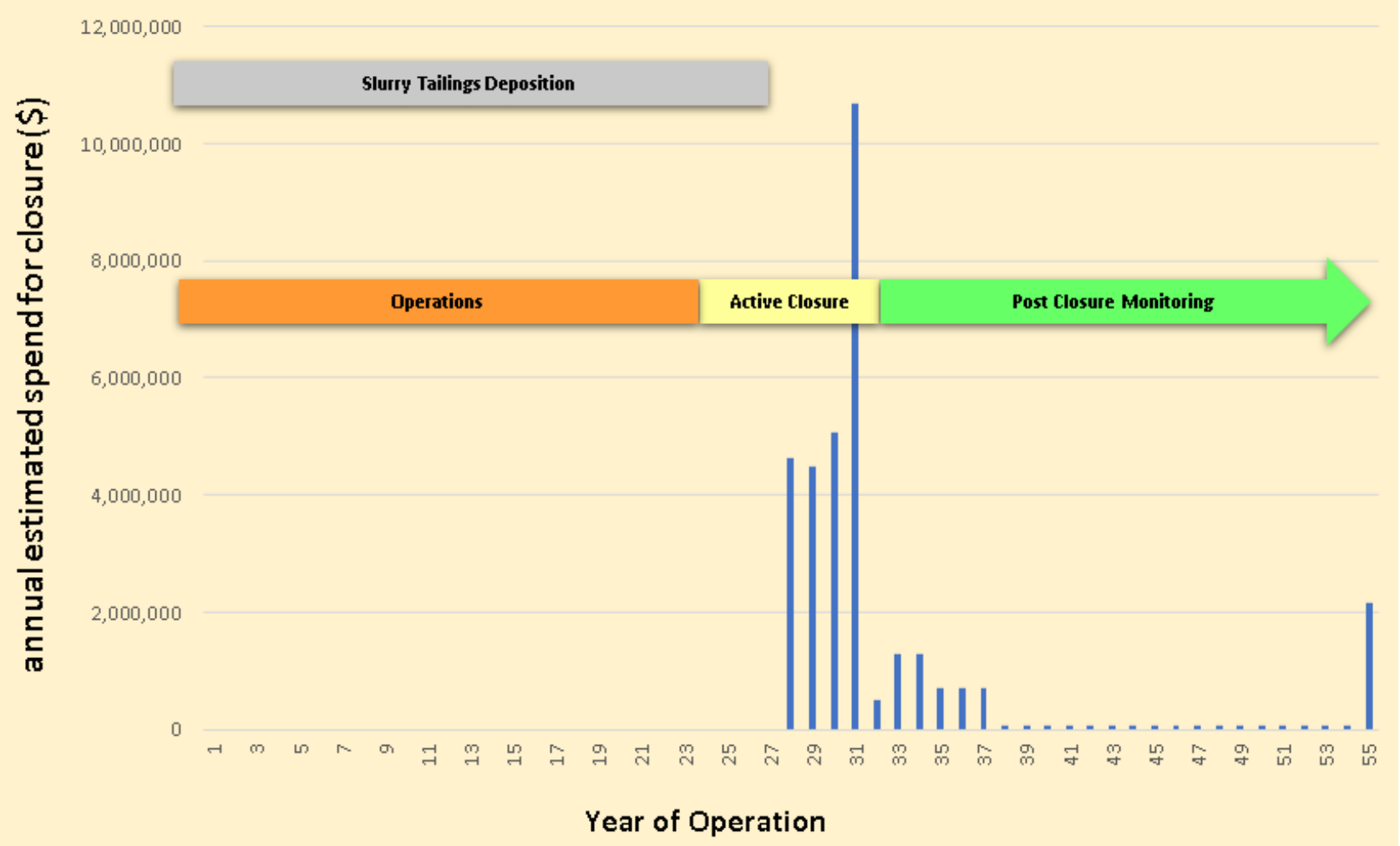

Figure 5 Illustration of expenditure for closure of slurry tailings storage facility

\section{A business case for dry cake tailings}

Pressure filtration technology has been around for a long time and is familiar equipment within process plants. However, it has only been over the past five years or so that that significant advances have been made by equipment manufacturers in managing large throughput and so the industry is starting to adopt the technology to treat whole tailings streams. The early converts have determined that filtration costs are offset by reliable water recovery.

The chart (Patterson et al. 2016) in Figure 6 is an illustration of case histories where filtered tailings management is in operation or planned and is reproduced here as an excellent barometer to test project tailings production parameters.

The second step is to test the tailings in terms of its ability to be dewatered and placed into a stable stack using conventional earthworks or alternate materials handling equipment.

At each site, tailings, project drivers and constraints are collectively unique. Some performance data can be transferred from other operations and relevant test work but for a relatively small cost, tailings can be tested for site-specific properties to enable a dewatering design concept to be prepared:

- Geotechnical laboratory test work on around $30 \mathrm{~kg}$ of tailings to establish particle size distribution (PSD), solids density and compaction parameters (optimum moisture content, maximum dry density).

- Bench scale testing by a dewatering equipment manufacturer can be achieved with four to six $30 \mathrm{~L}$ containers of $30 \% \mathrm{Sw} / \mathrm{w}$ slurry to provide a preliminary optimisation for the dewatering plant configuration. The input required is whether the purpose of the dewatering is to recover water or to reach a target dryness defined by \%S w/w. The parameters they test for include optimum feed solids content to reduce cycle time in pressure filtration, PSD by laser, chamber pressure, cake thickness, cycle time, and need for blow dry. 


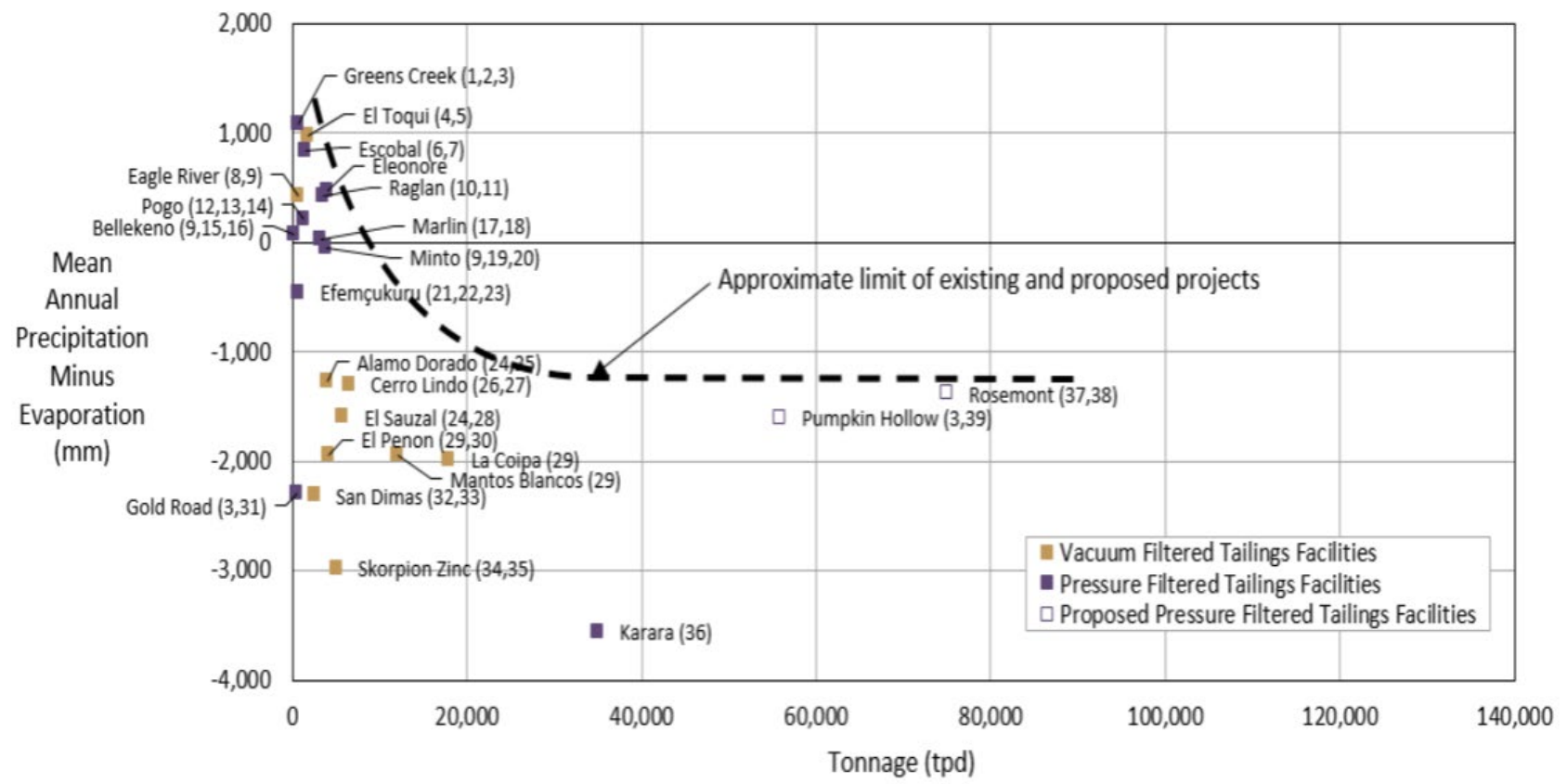

Figure 6 Case histories for filtered tailings management: dry tonnage versus climate (Patterson et al. 2016)

Clearly as the project develops in maturity, further geotechnical/civil test work and pilot plant test work will be required to confirm specific design assumptions. This may also include materials handling parameters if conveyors and stacking facilities are introduced to the design.

A comparison between slurry and dry stack tailings management cash flow is shown in Figure 7 that led to adopting dry stacking. The business case was evaluated on a LOM to Year 28 but also shows the opportunities for project extension.

In the slurry tailings option, the pond area is fully lined and the earthen starter embankment for TSF1 constructed prior to tailings deposition starting. The ongoing spend (blue) to Year 11 is for earthworks to raise the crest to the final level. Disposal into the facility starts in Year 6 with ongoing annual operating cost (orange). The purple is the closure associated with TSF1, while the turquoise elements in the chart represent the earthworks preparation of a second TSF2 to be ready to support future production with access to future ore resources.

In the dry stack option, the footprint of the facility is also required to be lined, but this is done sequentially as the stack advances. By bringing forward some of the CapEx into Years 4 and 5 to install the dewatering plant and infrastructure for dry cake production ultimately provides a more attractive solution financially in the medium to long-term along with many intrinsic environmental benefits. 


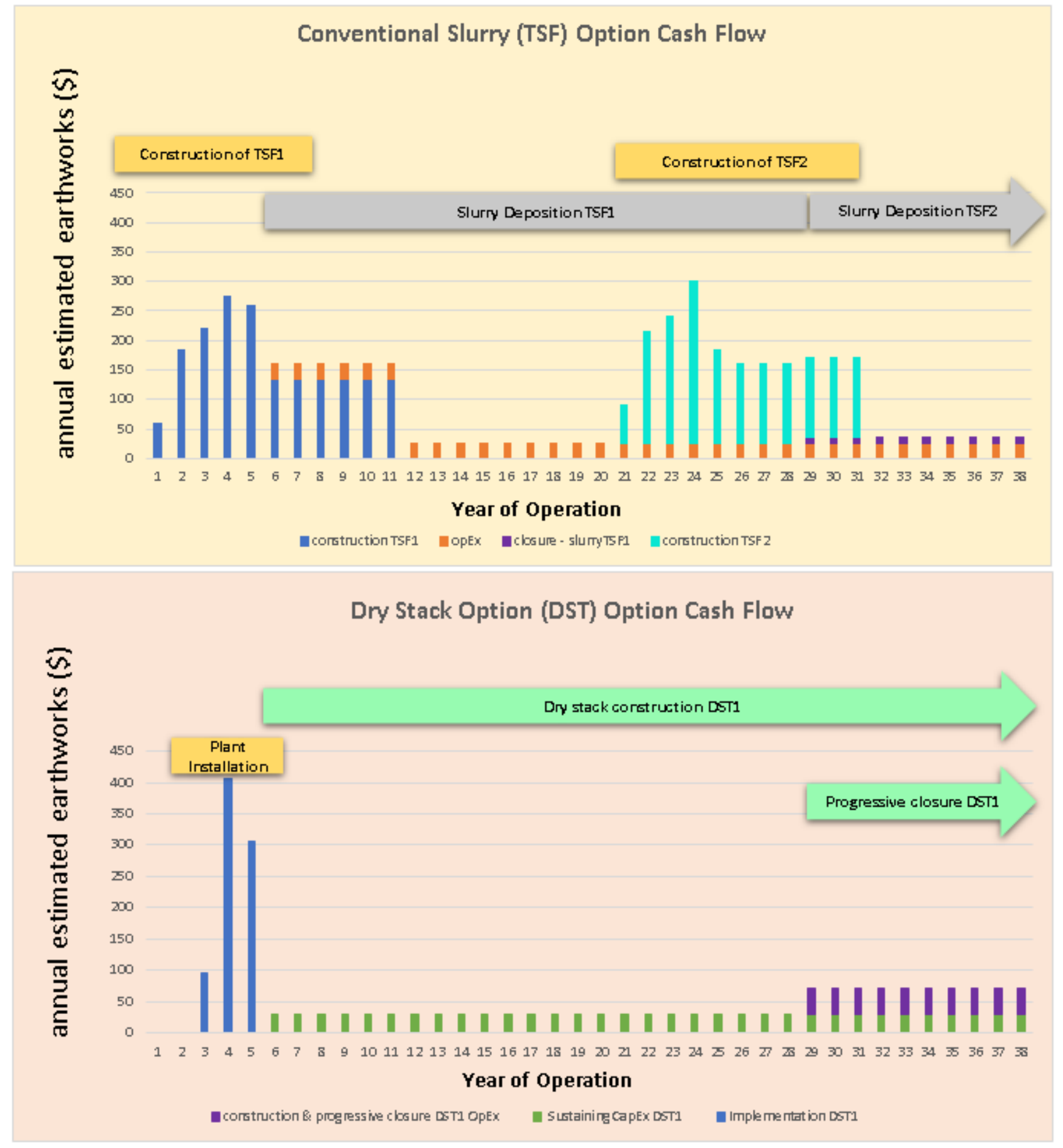

Figure 7 Example cash flow comparison of slurry versus dry stack tailings management

\section{Conclusion}

The key conclusions we wish to note are:

- Robust and commercially available dewatering equipment can produce 'dry' filter cake at a target solids content amenable to conventional earthworks construction. The technology and power consumption are continually under review and will improve equipment progressively.

- The 'dry' filter cake is placed into a stable landform that requires no retention dam, enhances water recovery, and enables progressive closure. This form of tailings management can have large environmental and social benefits since it removes the risk of dam failure. 
- Viewing the costs of tailings storage over the longer term or life-of-project will influence the selection of the most appropriate tailings management approach.

- The future of tailings management will trend towards dry filter cake and dry stacking.

\section{Acknowledgement}

Many thanks to Beca Ltd for supporting the authors in the preparation of this paper.

\section{References}

Aitken, S \& Kemeid, F 2016, 'Evolution to dry stack tailings for the Vale Nouvelle Calédonie Nickel Project, Proceedings Tailings and Mine Waste, Colorado State University, Denver, pp. 817-830.

Davies, MP \& Rice, S 2001, 'An alternative to conventional tailings management - "dry stack" filtered tailings', Proceedings of the Eighth International Conference on Tailings and Mine Waste '01, Balkema, Rotterdam, pp. 411-422.

International Council on Mining and Metals 2018, Integrated Mine Closure - Good Practice Guide, 2nd edn, p. 9.

Patterson, K, McLeod, H, Hegadoren, D, Parkinson, G, Williams, P \& Murphy, B 2016. 'Are Filter Tailings Practical for a High Production Mine in a Cold, Wet Climate?', Proceedings Tailings and Mine Waste, Colorado State University, Denver, pp. 359-371. 
